\title{
LOW-COST APPROACH TO THE DESIGY AND FABRICATION OF A LOX/RP-1 INJECTOR
}

\author{
M.D. Shadoan* and D. Sparks \\ Space Transportation Directorate. Marshall Space Flight Center. MSFC. Alabama
}

\begin{abstract}
NASA Marshall Spalce Flight Center MSFCi has designed. built. and is currently testing Fastrac. a liquid oxygen (LOX)/RP-1 fueled $60 \mathrm{~K}-1 \mathrm{~b}$ thrust class rocket engine. One facet of Fastrac which makes it unique is that it is the first large-scale engine designed and developed in accordance with the Agency's mandated "faster, better, cheaper" (FBC) progran policy. The engine was developed under the auspices of MSFC's Low Cost Boost Technology office.
\end{abstract}

Development work for the main injector actually began in 1993 in subscale form. In 1996, work began on the full-scale unit $\approx 1 \mathrm{yr}$ prior to initiation of the engine development program. In order to achieve the value goals established by the FBC policy. a review of traditional desien practices was necessary. This internal reevaluation would ultimately challenge more conventional methods of material selection. design process. and fabrication techniques. The effor was highly successful. This "new way" of thinking has resulted in an innovative injector design. one with reduced complexity and significantly lower cost. Application of lessons learned during this effort to new or existing designs can have a similar effect on costs and future program successes.

\section{INTRODUCTION}

Development of space hardware has traditionally been done with the philosophy that the designer must use all available technological resources to maximize performance. This philosophy placed great emphasis on high thrust to weight ratios that greatly increased the cost and complexity of space hardware. However, in recent years of budget reductions and downsizing, the Government as a whole has been tasked with reinventing itself, to adopt

\footnotetext{
* Nember

Copsright $\mathrm{c}$ z(m) by the American Institute of Aeronautics and Astronautics. Inc. No copyright is asserted in the United States under Title 17. U.S. Code. The U.S. Government has a royalty-free licenie to exercise all rights under the copyright claimed herein for Governmental Purposes. All other rights are reserved by the copyright owner.
}

an $\mathrm{FBC}$ attitude when devising and developing new program acyuisitions. Applying this to the design of space hardware means we must adapt new practices that result in inexpensive and reliable components. To accomplish these goals. the designer must incorporate fabrication experience. such as material and process selection. along with innovative design approaches.

The initial goal was to build a LOX/RP-1 injector that exhibits good performance and wall compatibility when operated with an ablative thrust chamber and nozzle assembly at a fraction of the cost of a conventional equivalent unit. The development injector was designed. tabricated. and tested in 16 months. The design was then transformed. with minor modifications. into the main injector for the Fastrac engine.

The injector design, fabrication processes, verification procedures. and test results are detailed in this paper. Also, a cost breakdown is given for manufacturing the LOX/ RP-I injector.

\section{DESIGN DESCRIPTION}

The Fastrac 60K-lb LOX/RP-1 main injector is shown in figure 1. Excluding the gimbal assembly, the entire component is made up of only three parts: the core. LOX dome cap. and faceplate. Additionally, the injector contains several unique features, resulting in a low-cost design.

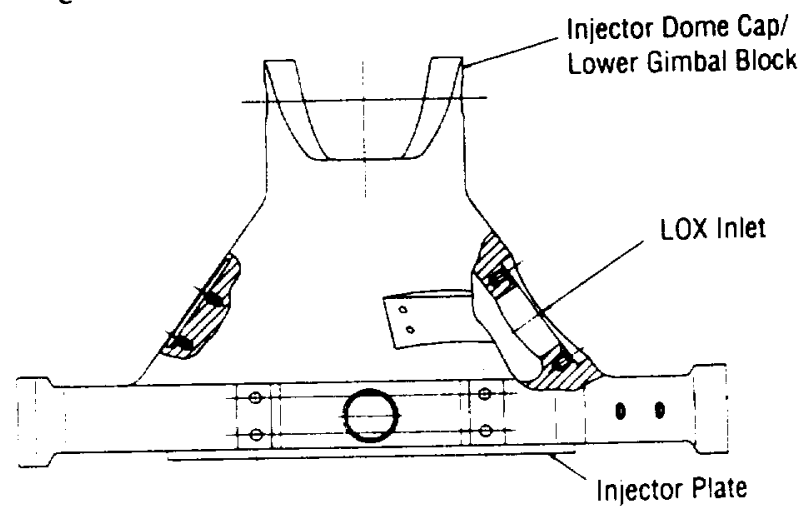

Fig. 1. LOX/RP-1 $60 \mathrm{~K}$ injector. 


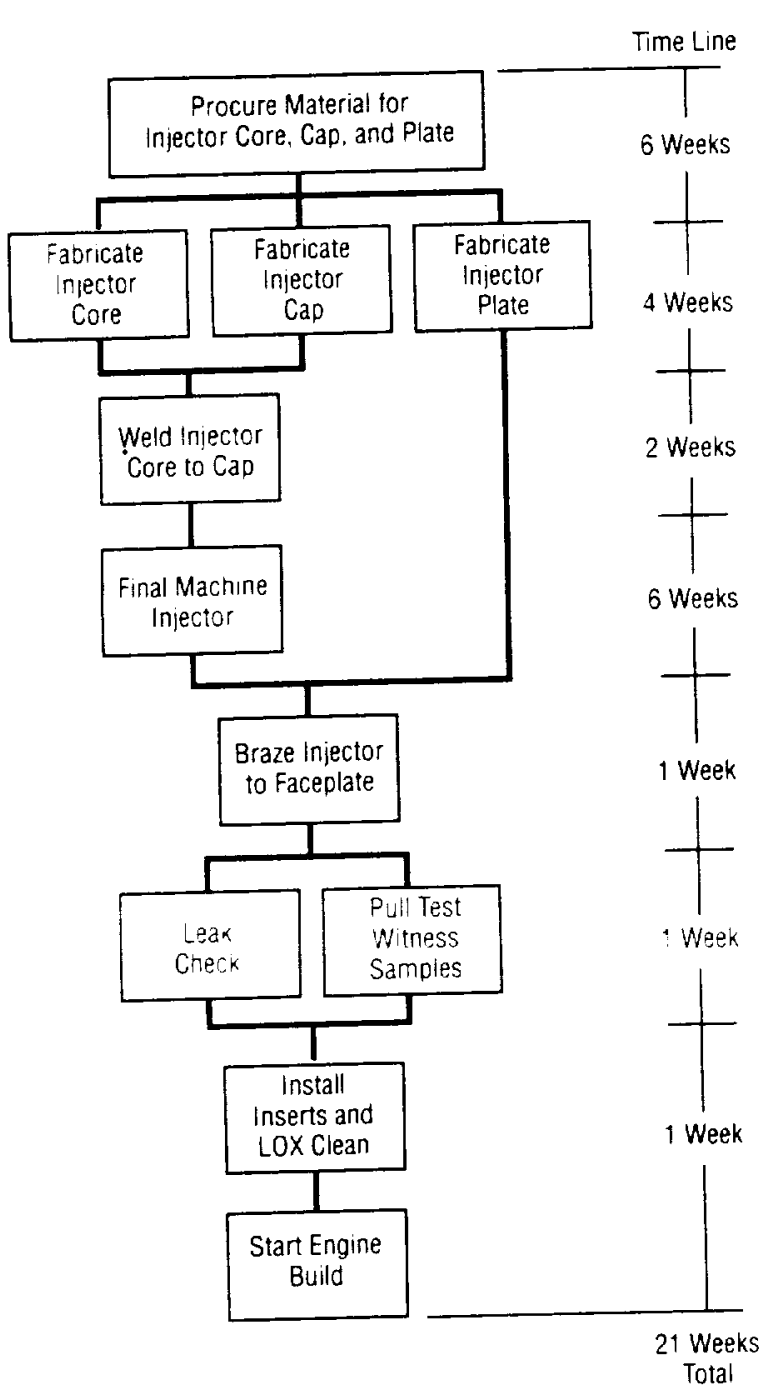

Fig. 5. Fabrication process.

To enhance the dimensional stability of the injector, a stress relief cycle is performed to remove the residual stresses induced by prior fabrication processes. The final machining of the injector assembly will remove any distortion introduced by welding. Also, all key interfaces such as gimbal location, attachment points. and braze surfaces are tinal machined.

The next process is to braze the injector plate to the injector core assembly by a vacuum brazing operation. Material selection was key in making this braze reliable and cost effective. The $304 \mathrm{~L}$ stainless steel injector core will braze exceptionally well to an oxygen-free copper faceplate without the requirement of a plating process. The specifics of the brazing operation can be found in MSFC-SPEC2761. Before brazing, the injector plate is prepared by grinding the surface to be brazed to a thatness of 0.0005 in. in the restrained condition. This ensures that all high spots are removed and promotes good braze flow.
SILCORO-75 braze alloy is applied directly to the injector core lands manually with a syringe-type applicator. Any holes smaller than 0.030 in. are filled with a braze flow inhibitor to prevent the alloy from wicking into the holes during the braze operation. The injector plate is properly aligned using index marks on the plate and injector, then the injector is place on the injector core. A centering pin prevents radial movement during brazing. Reticulated foam is placed on top of the injector and a stainless steel plate is added on top of the foam to provide even weight distribution during brazing. At the same time. two complementing witness samples are also brized for later use to determine the integrity of the braze joint.

The final step is to install inserts and proceed with braze verification.

\section{BRAZE VERIFICATION}

The braze joint is veritied if it meets two criteria: A tensile test of the witness samples used during brazing and a vacuum check to determine if there are leak paths in the interpropellant joints. The witness samples must meet tension pull test requirements set forth in MSFC-SPEC2761 . During the vacuum test the LOX side of the injector is isolated from ambient pressure by sealing it with closeout plates and plugs in the instrumentation ports. A vacuum is drawn on the part using a diffusion pump and is then isolated from the pump. The vacuum test must meet the criteria of MSFC-PROC-2953: i.e.. it must show no appreciable leakage for a period of 15 minutes or the part is rejected.

\section{STRLCTURAL ANALYSIS}

A detailed report on the stress analysis performed on the main injector will be documented in an internal memo that will be released later. This paper only address two areas of concern as cited by Sutton: ${ }^{1}$ Stresses on the injector plate due to the large combustion forces and keeping a positive seal between the fuel and oxidizer to prevent internal tires.

The high stress in the injector plate is due to the pressure forces and thermal gradients derived from the combustion process. Due to thermal growth in the injector plate, the internal lands and the injector plate undergo plastic deformation. Yet, the ductility of the $304 \mathrm{~L}$ stainless steel and oxygen-free copper are large enough to prevent any low-cycle fatigue issues.

The LOX is sealed from the RP- 1 by the braze joint. which measures $0.1 \mathrm{in}$. The braze alloy is sufficiently ductile to prevent any damage to the braze joint. 


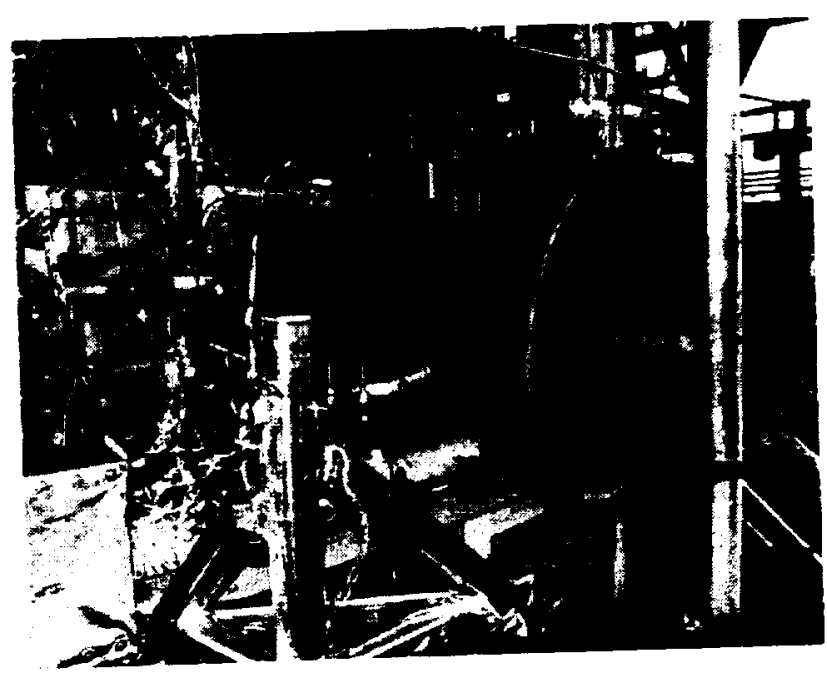

Fig. 8. 15:1 TCA installed in TS116.

\subsection{TCA Start}

The TCA is started oxygen rich and uses the hypergol mixture triethylaluminum and triethylboron (TEA/TEB, as the ignition source. At the component level. the injector is tirst themally conditioned by prechilling the oxidizer side of the injector with a reduced flow rate of LOX for 5-10 sec. immediately prior to committing to automated control. Once autosequence has begun, the programmed control again prechills the injector by partially opening the main oxidizer valve (MOV) for 2 seconds prior to initiating ignition with TEATEB flow to the chamber. The chamber pressure $\left(P_{L}\right)$ rises as the hypergol reacts with the LOX. Once a threshold $P_{c}$ is reached. the main fuel valve is fully opened while the fuel purge is cycled off. At this point $P_{c}$ builds rapidly, and once a second $P_{0}$ threshold level is reached. the MOV is fully opened. This sequence takes $=2.4 \mathrm{sec}$ and is a reasonably good representation of the actual engine start time (fig. 9).

\subsection{TC.A Mainstage}

Steady-state design operating conditions for the main injector are presented in table 2. Figure 10 shows $P_{c}$ versus time for both engine and component level operation. Run durations are limited to $150 \mathrm{sec}$ at TS1 16 due to the LOX tank capacity. A view of the TCA during mainstage operation is shown in tigure 11 .

\subsection{TCA Shutdown}

A tuel-rich cutoff sequence. designed to minimize the possibility of high-temperature damage to the injector. terminates TCA operation. $\mathrm{GN}_{2}$ purges are utilized to prevent residual propellants from backflowing through the elements of the faceplate and into the supply manifolds.

TCA Component and Engine Start Comparison

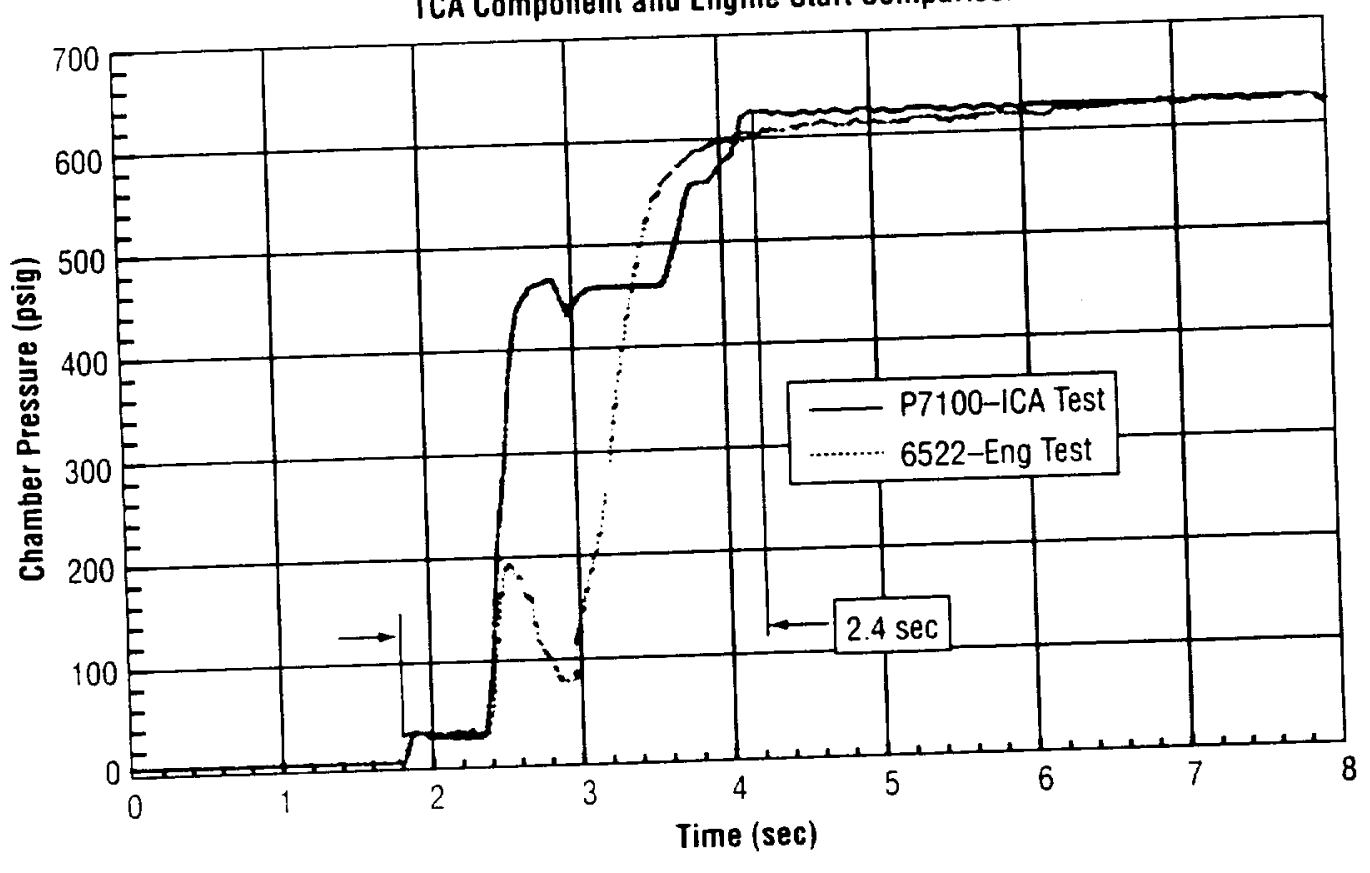

Fig. 9. TCA versus engine start $P_{c}$ profile. 
strength at temperatures $>300^{\circ} \mathrm{F}$. Therefore, temperatures within the injector acoustic cavity had to be considered. since it is in intimate contact with the mounting flange of the chamber. The thermal environments in this region clearly play a major roll in meeting the life requirements of the component.

The engine power balance and the requirements of the $\mathrm{X}-34$ vehicle established the operating conditions for the main injector. Even though the injector was designed to be low cost. it obviously must still meet minimum performance and stability requirements. Component test results indicate all of these goals have been achieved: however. much engine testing remains to fully determine system pertormance margins.

Results of tests performed thus far are as follows:

All testing has indicated that the goals of uniform temperatures and wall compatibility have successfully been met. Chambers tested with the baseline film cooling percentages have not shown any evidence of high themal stress or wide swings in temperature protiles. Even after $=350 \mathrm{sec}$ of testing on a single chamber. the region near the injector remains streak free, and only minor indications of temperature stress in the form of material delaminations in the ablative wrap have occurred.

Extensive measurements have been made of gas remperatures within the acoustic cavity and metal temperatures near the wall of the cavity. Results indicate. with the exception of brief spikes during ignition. that the acoustic cavity region operates consistently at temperatures well below $1000^{\circ} \mathrm{F}$. These low temperatures are largely responsible for the lack of negative structural margins (low-cycle fatigue) on the injector.

Faceplate cooling appears more than adequate for the heat loads generated during the combustion process. None of the hot fire testing to date has indicated any large thermal variances due to hot gas recirculation or radial winds near the copper faceplate. There has been no pitting or discoloration of any kind and no deterioration of the comer of the taceplate, which forms one side of the acoustic cavity aperture.

Performance for the TCA is based on the characteristic exhaust velocity efficiency $\left(\eta_{C^{*}}\right)$. Chamber pressure measurements are made in a plane even with the faceplate. and one-dimensional isentropic relationships are used to derive the nozzle stagnation pressure $\left(P_{n s}\right)$. Nozzle stagnation pressure, along with flow rates calculated from data obtained from inline cavitating venturies, are used to determine the actual $C^{*}$. That value is then ratioed against the theoretical performance (determined from performance prediction codes at the same conditions) to determine $\eta_{C}$. It is worth noting that the data shown in figure 9 shows that the $P_{c}$ continues to rise during the test. Since flow rate remains constant due to the cavitating venturies, the gradual pressure rise is a direct result of carbon buildup in the chamber throat during TCA operation. Theretore, efficiency values are quoted based on measured pretest throat diameters and on data gathered early in the test. before significant accumulations of carbon can occur.

Dynamic stability goals were based on similarities with the MA-5 sustainer engine. The requirement is for no spontaneous instabilities in development or flight hardware ground tests. Additionally, 50 consecutive stable tests to mainstage conditions are required to meet this criteria, with no pressure oscillations $>10$ percent peak to peak. The ultimate goal of the program is to exceed this minimum requirement by demonstrating dynamic stability aicording to industry guidelines (i.e. with bomb tests). Some bomb tests have already been pertormed with mixed revults. However, no spontaneous instabilities have occurred, and many of the 50 required engine level tests have already been performed with no anomalies. Future manpower and funding resources will ultimately determine if bomb stability testing can continue.

\section{FLTURE TESTING}

TCA testing at MSFC is set to resume in late 2000 and will include tests of the fleet leader chamber. chambers with known manufacturing anomalies, and tests of an improved performance injector design. Additionally. several tests are planned using a regeneratively cooled chamber designed and built specifically for the $60 \mathrm{~K}$ injector.

Engine test objectives at SSFL are the completion of development and verification testing of the engine system. These tests include full and extended duration runs. testing with environmental conditioning, margin testing. and calibration verification. Future testing at either SSFL or SSC will conclude the test program with certification of the final design.

Tests of the gimbal bearing will also be conducted under engine load conditions in an integrated system test at an alternate location.

Prior to the first flight of the $X-34$, the engine will be installed into the vehicle. and an integrated static test will be performed at White Sands Missile Range in New Mexico. 



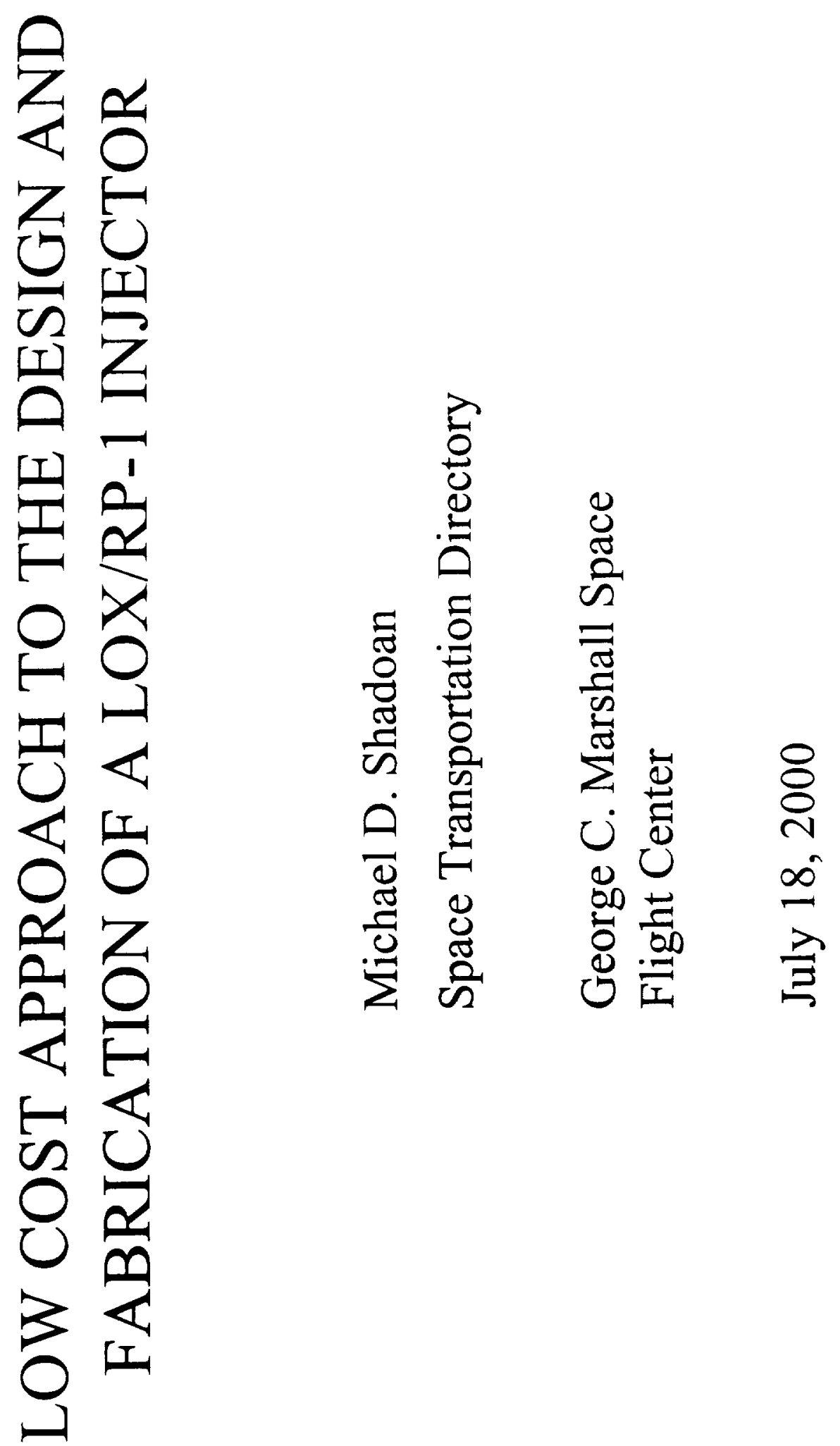




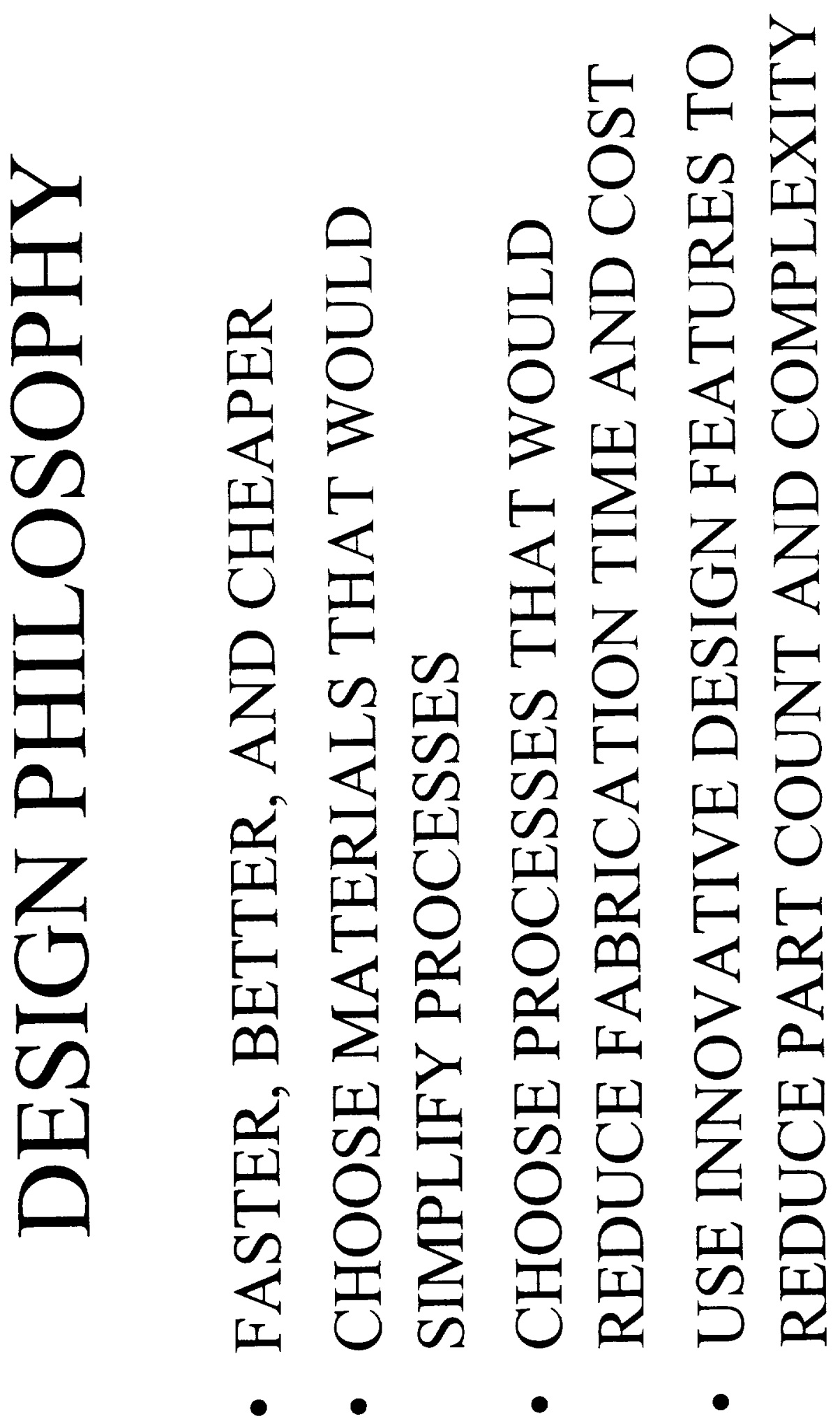


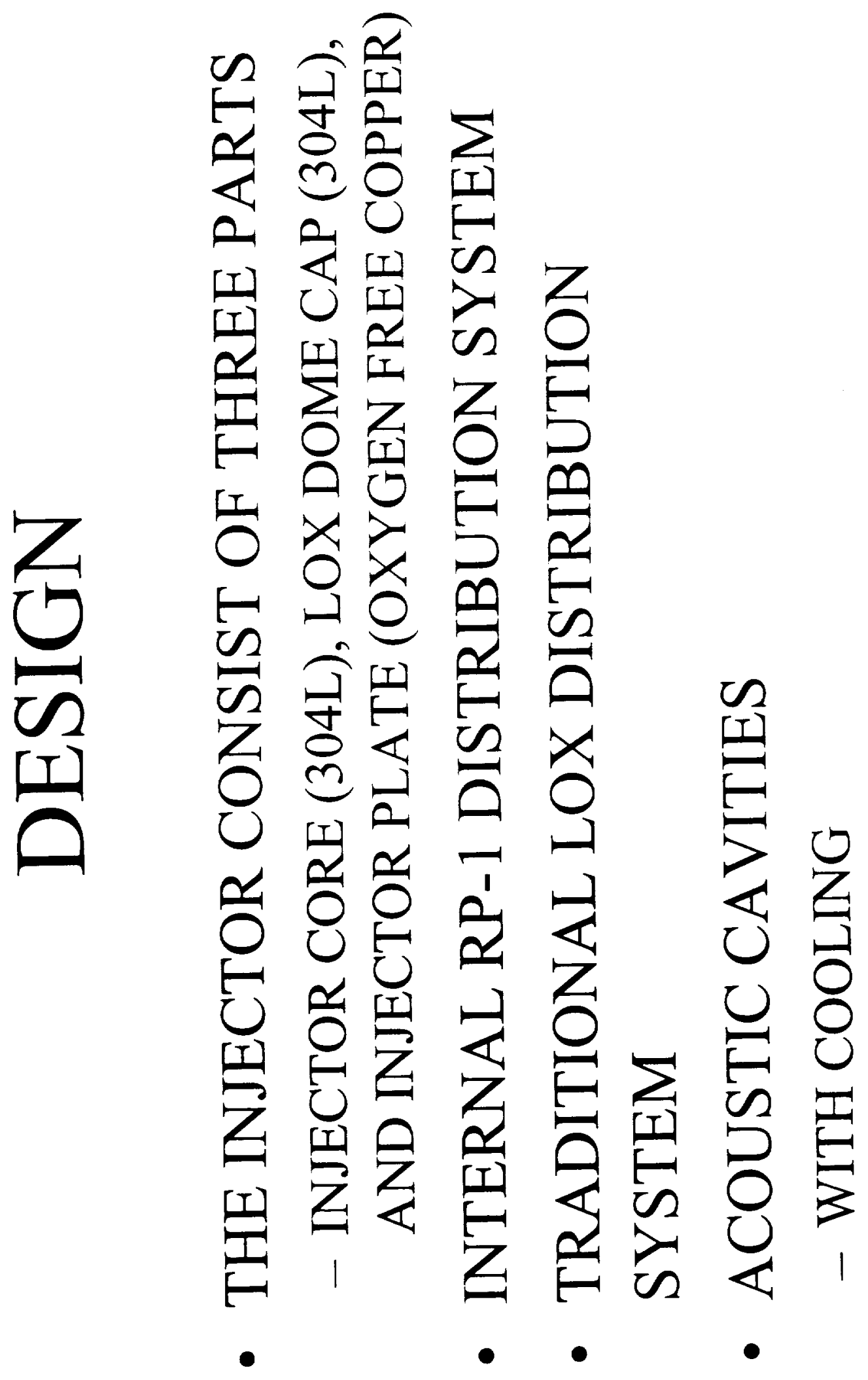




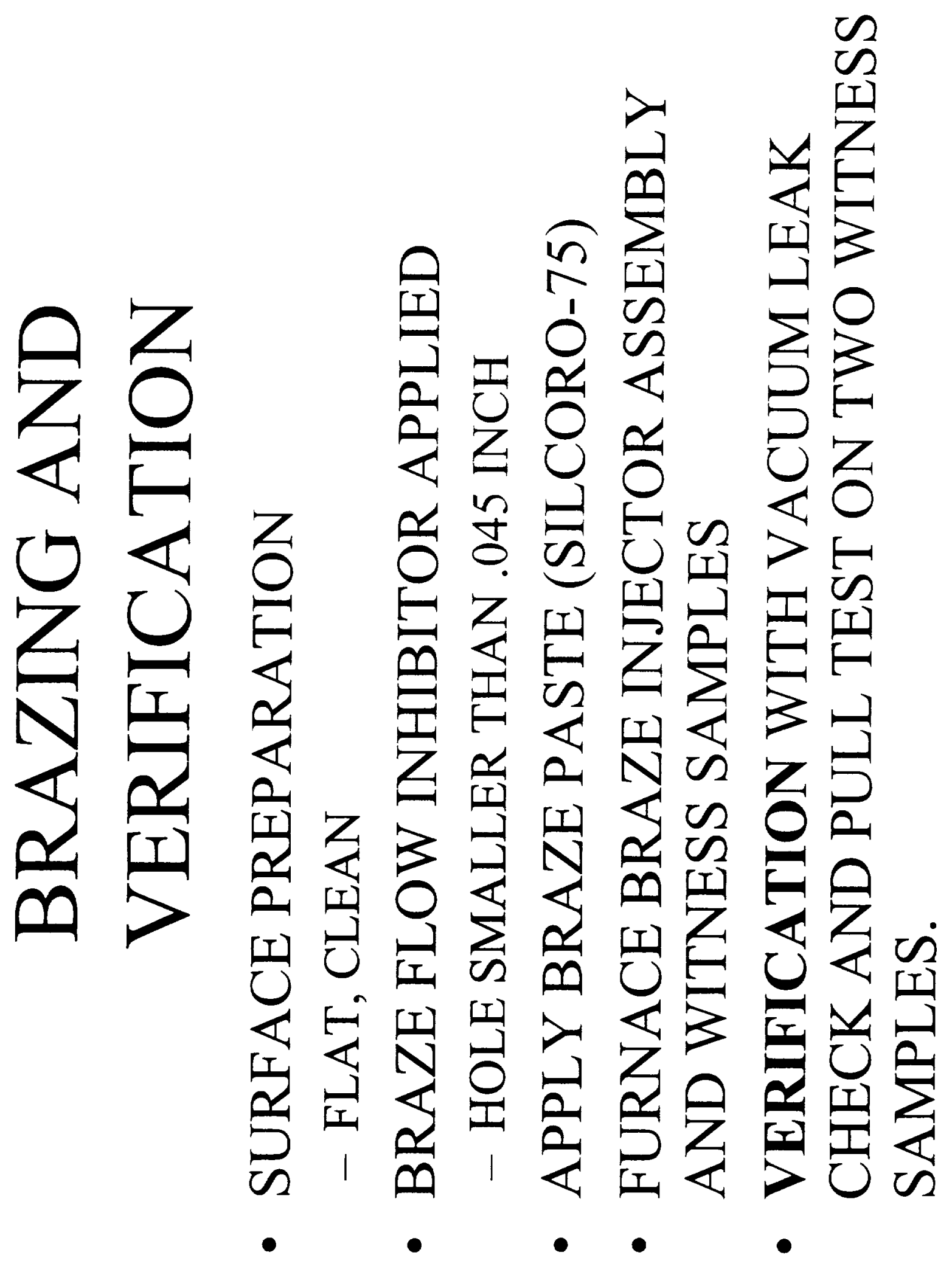




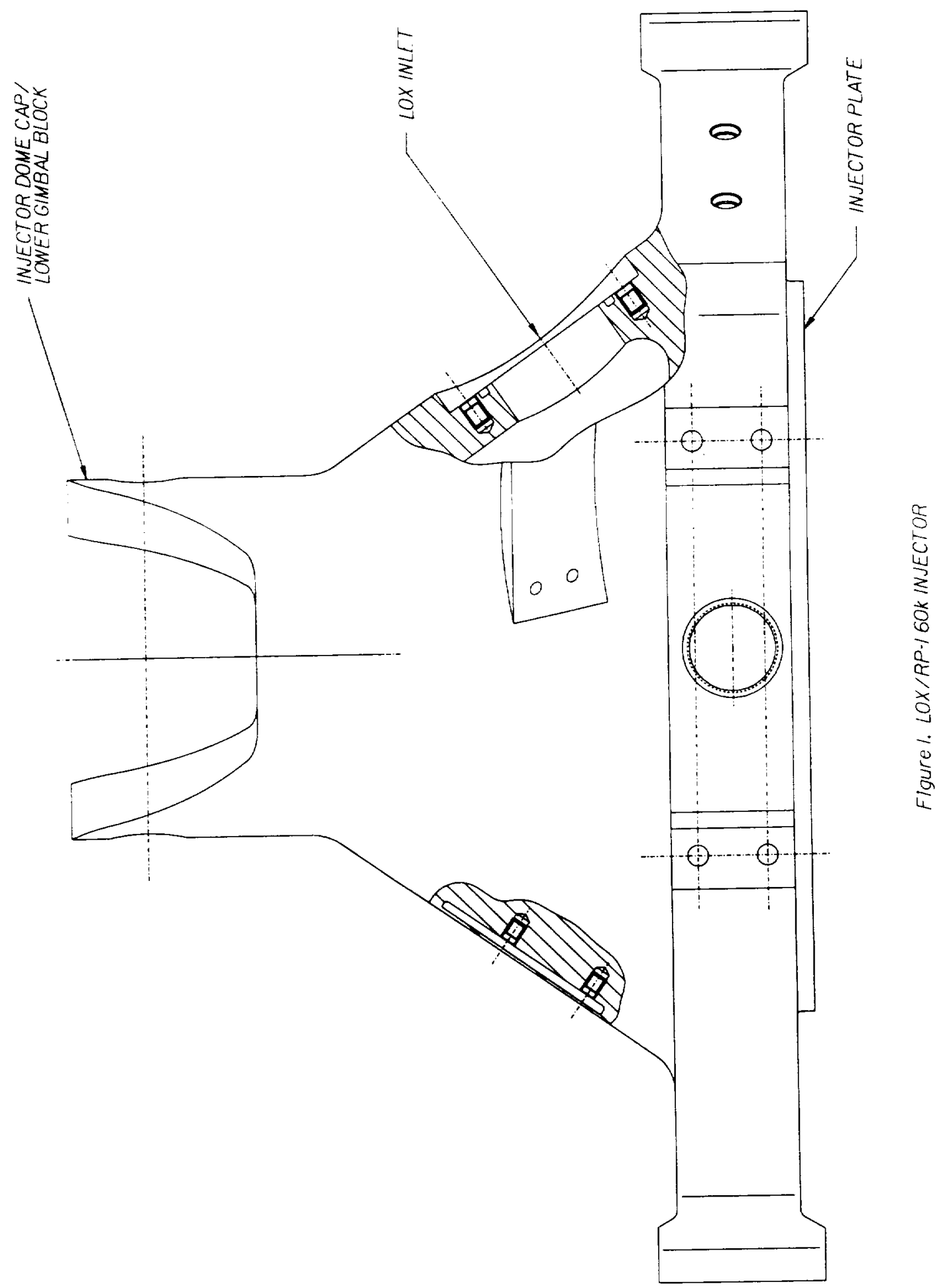




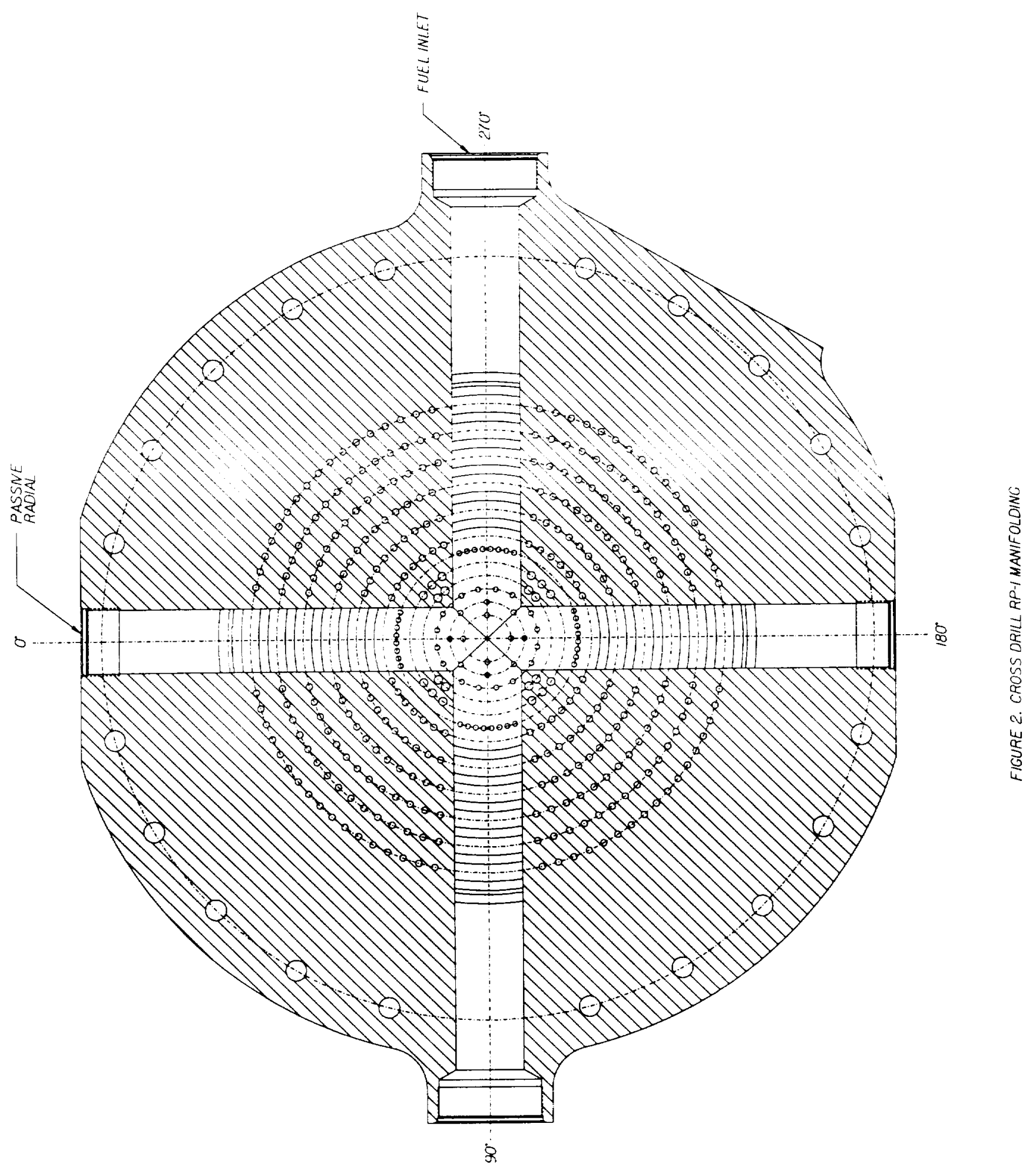




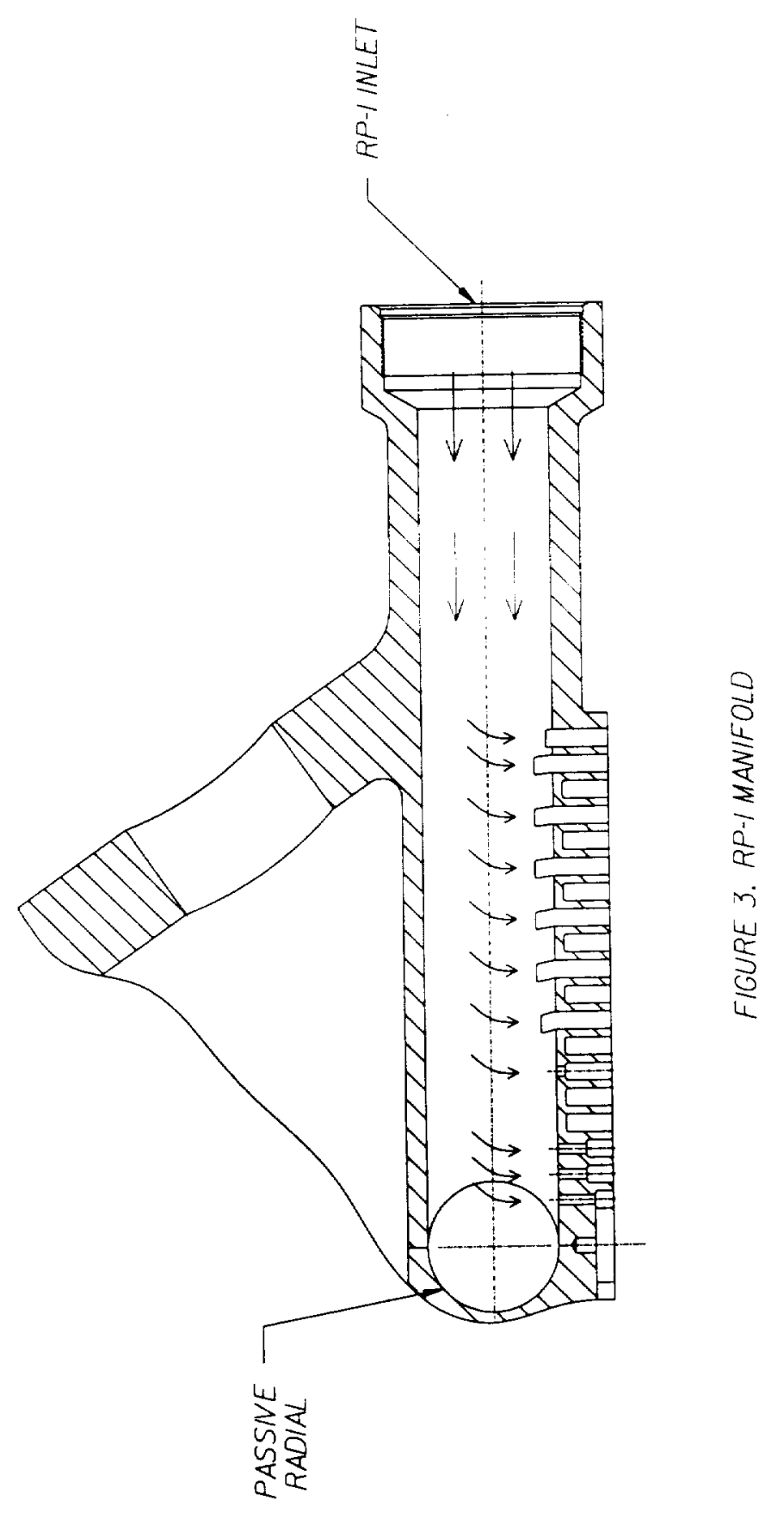




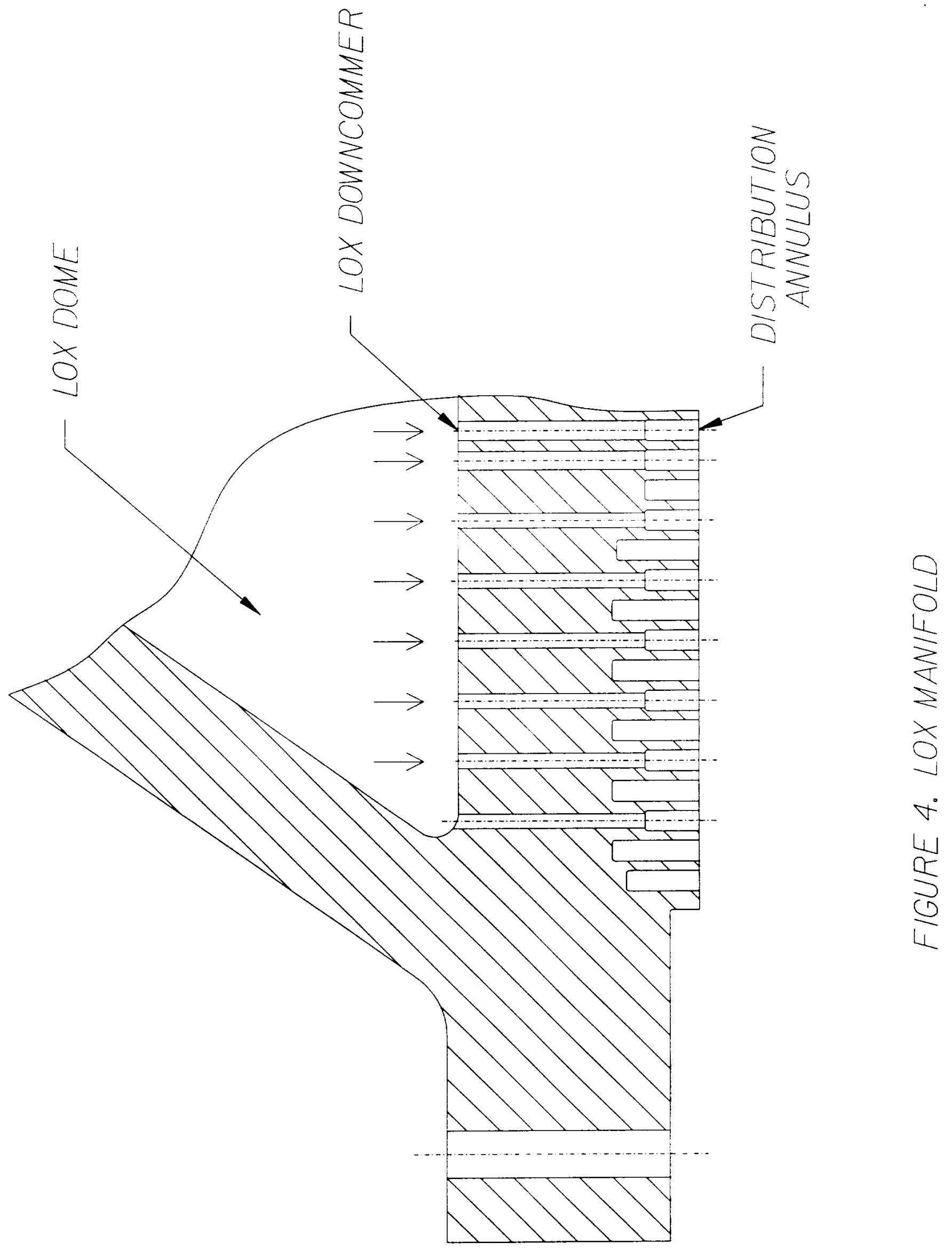




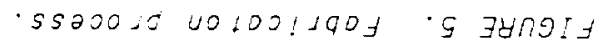

$7 \forall 101$

$5 \times 3 \exists M+2$

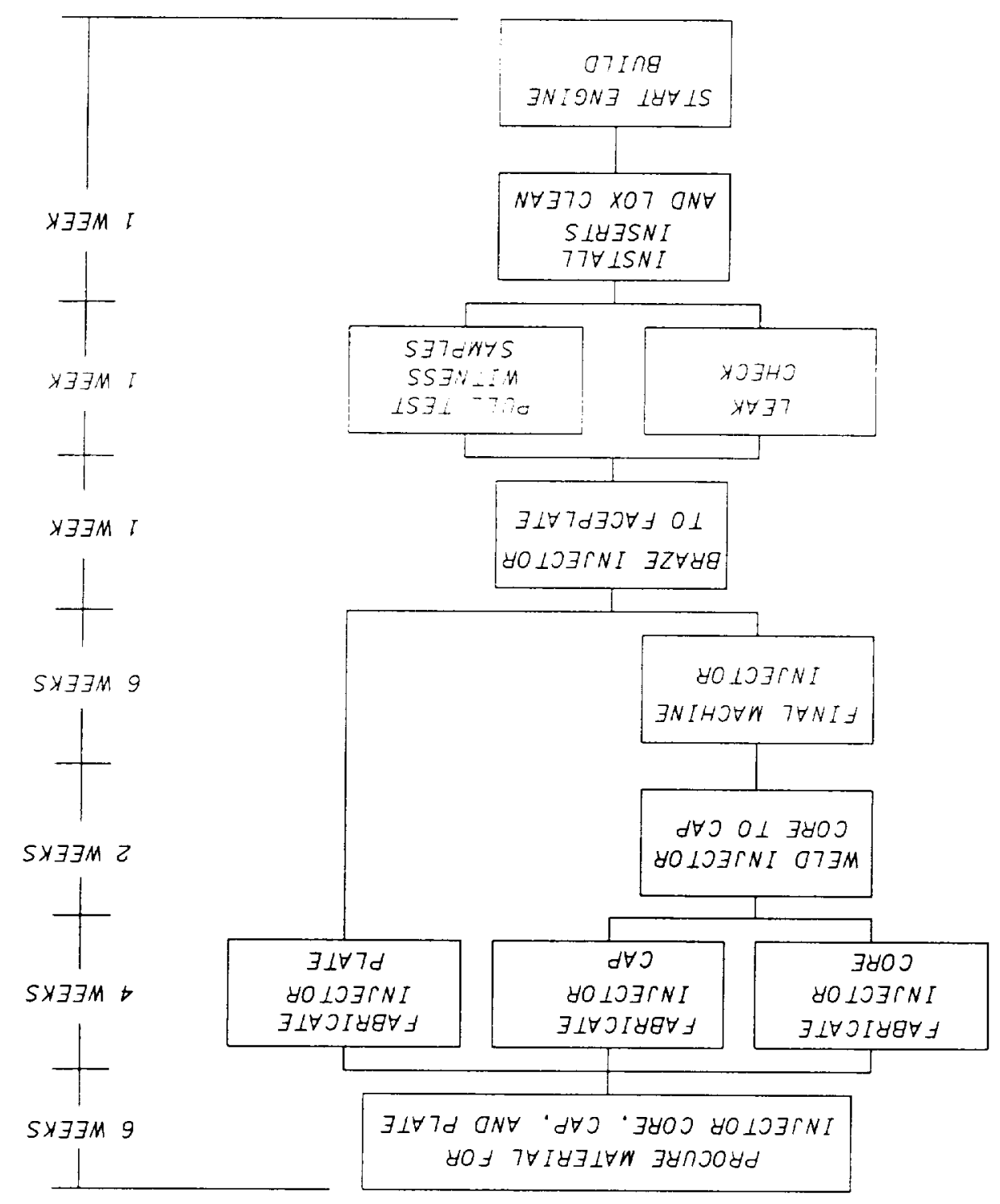

$\exists N I 7 \quad 3 W I L$ 


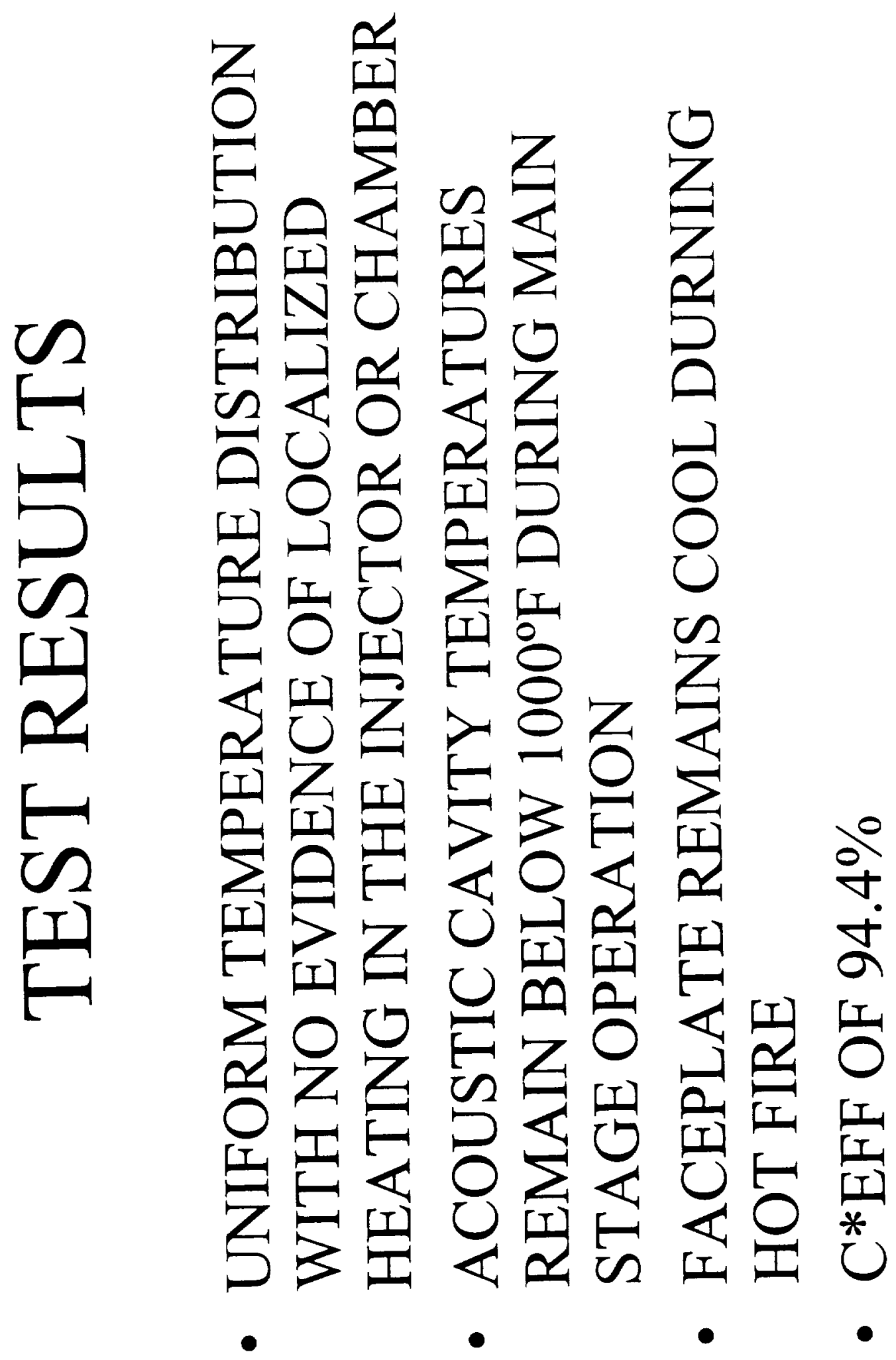




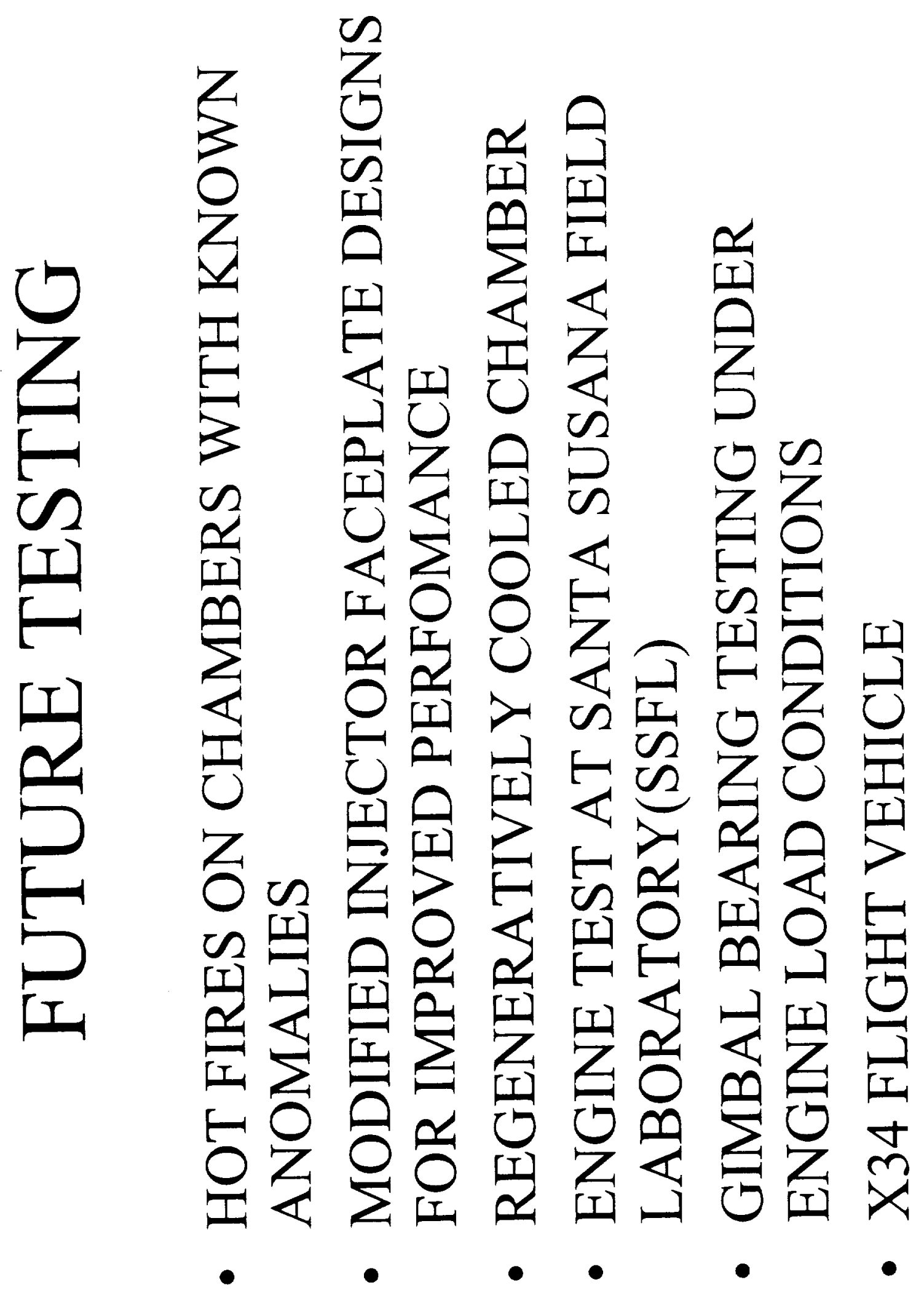




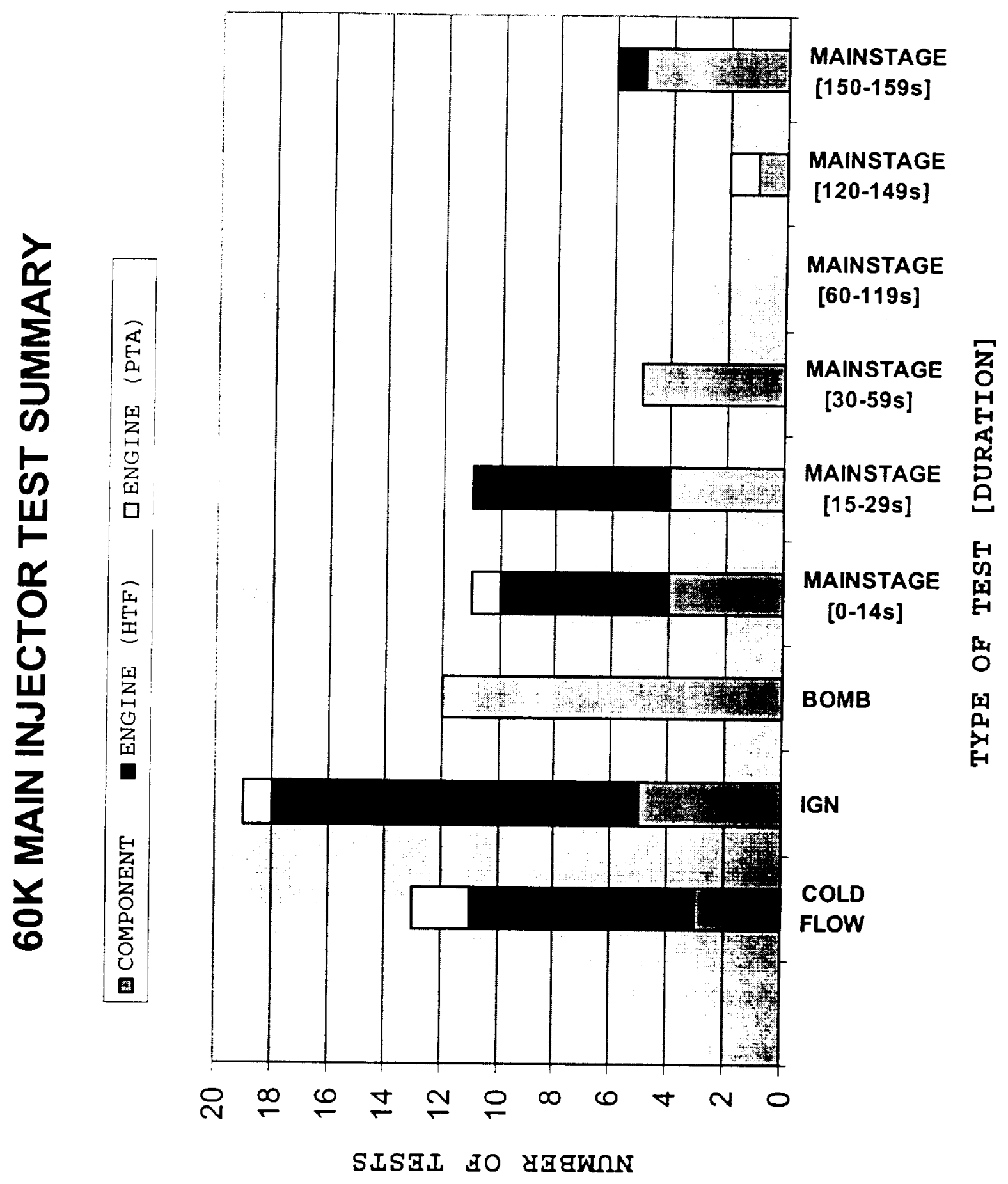




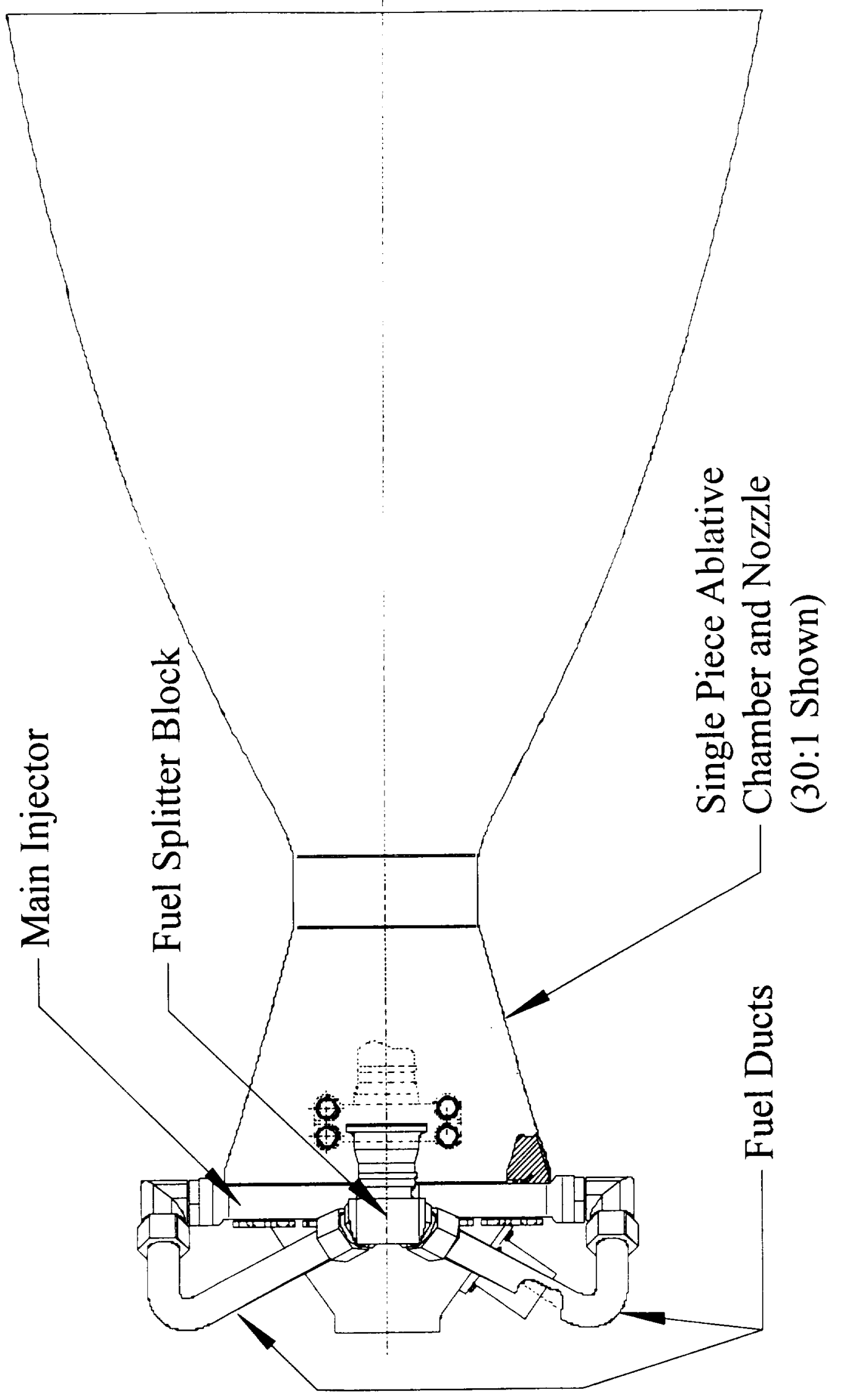




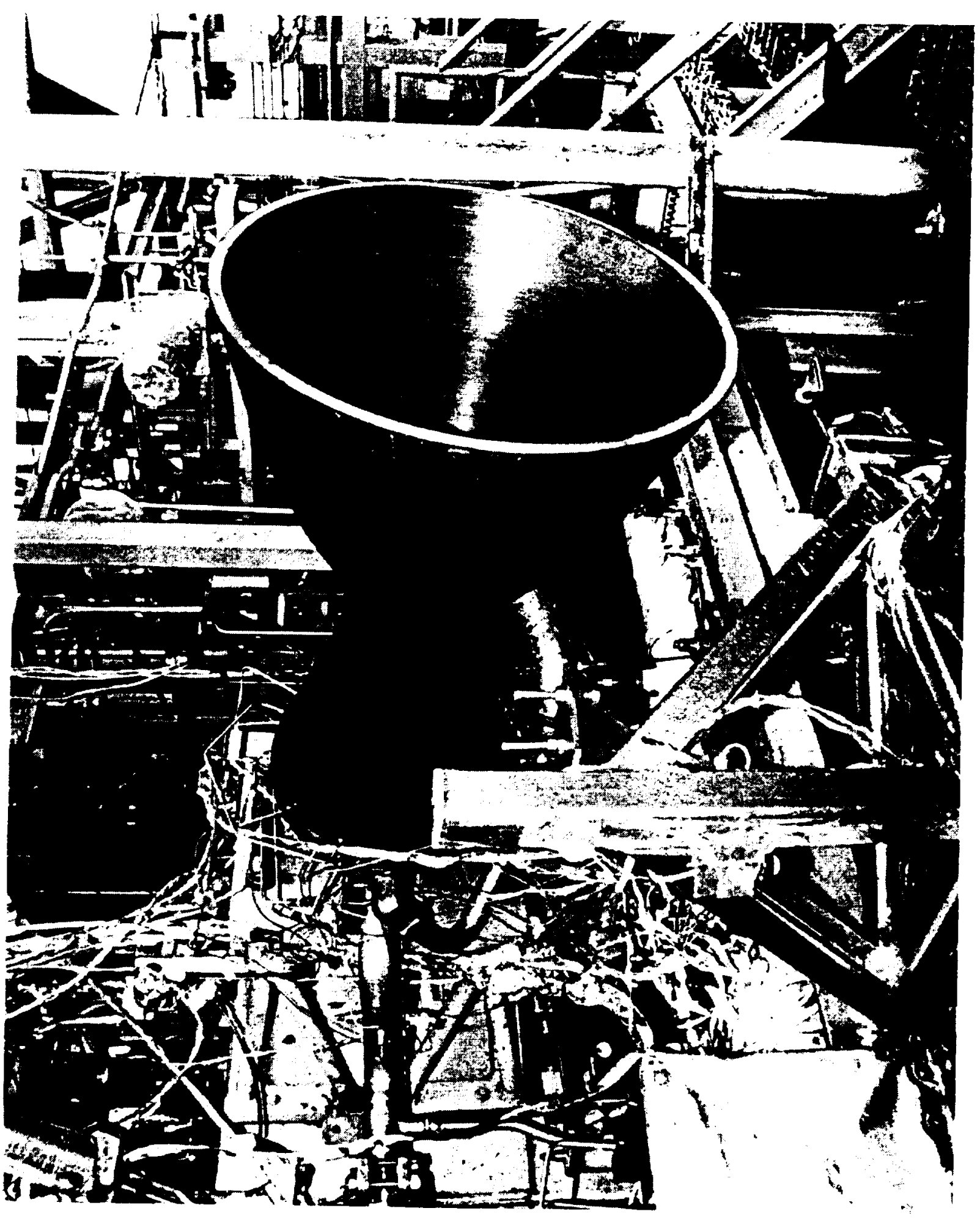




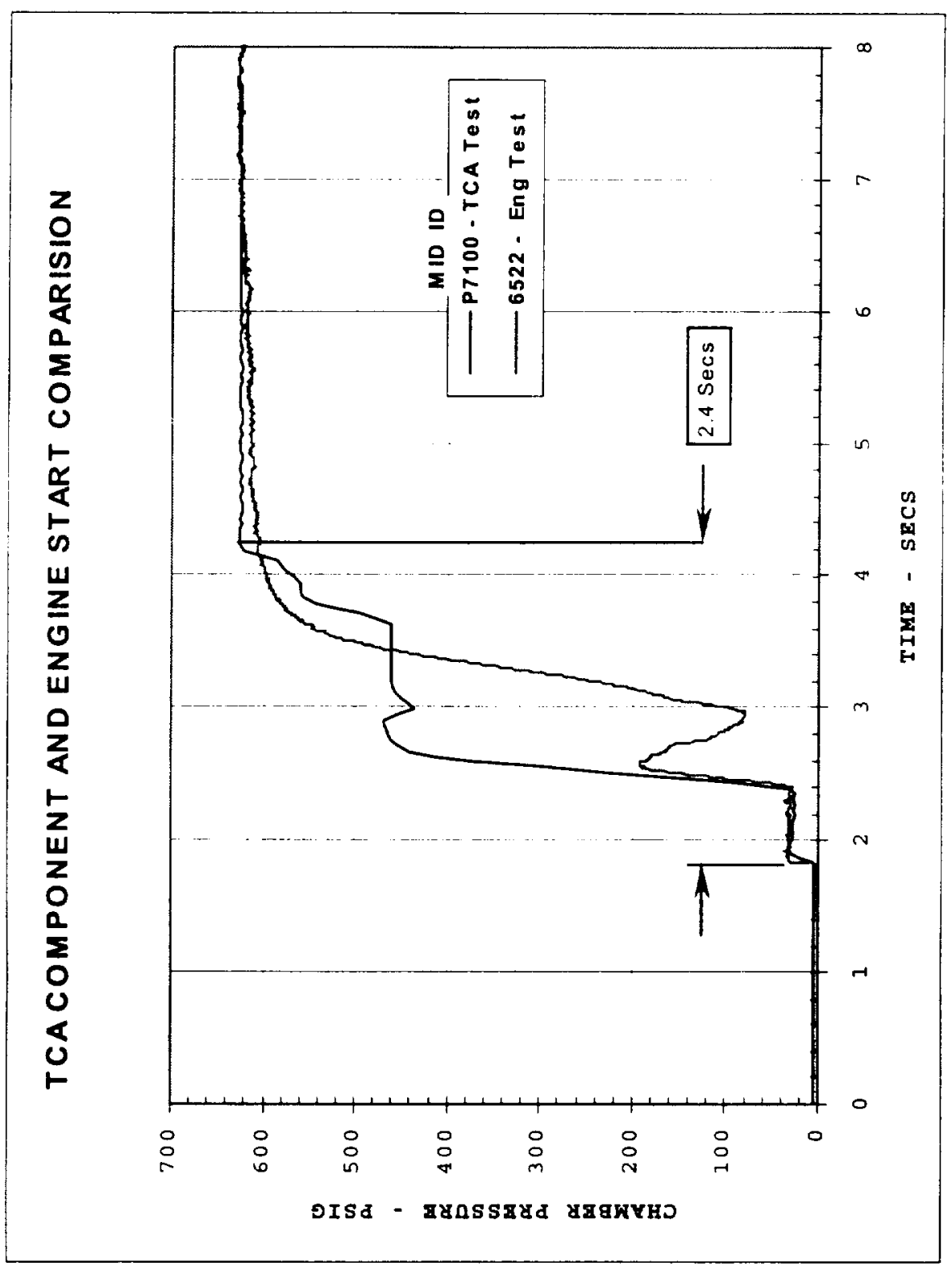




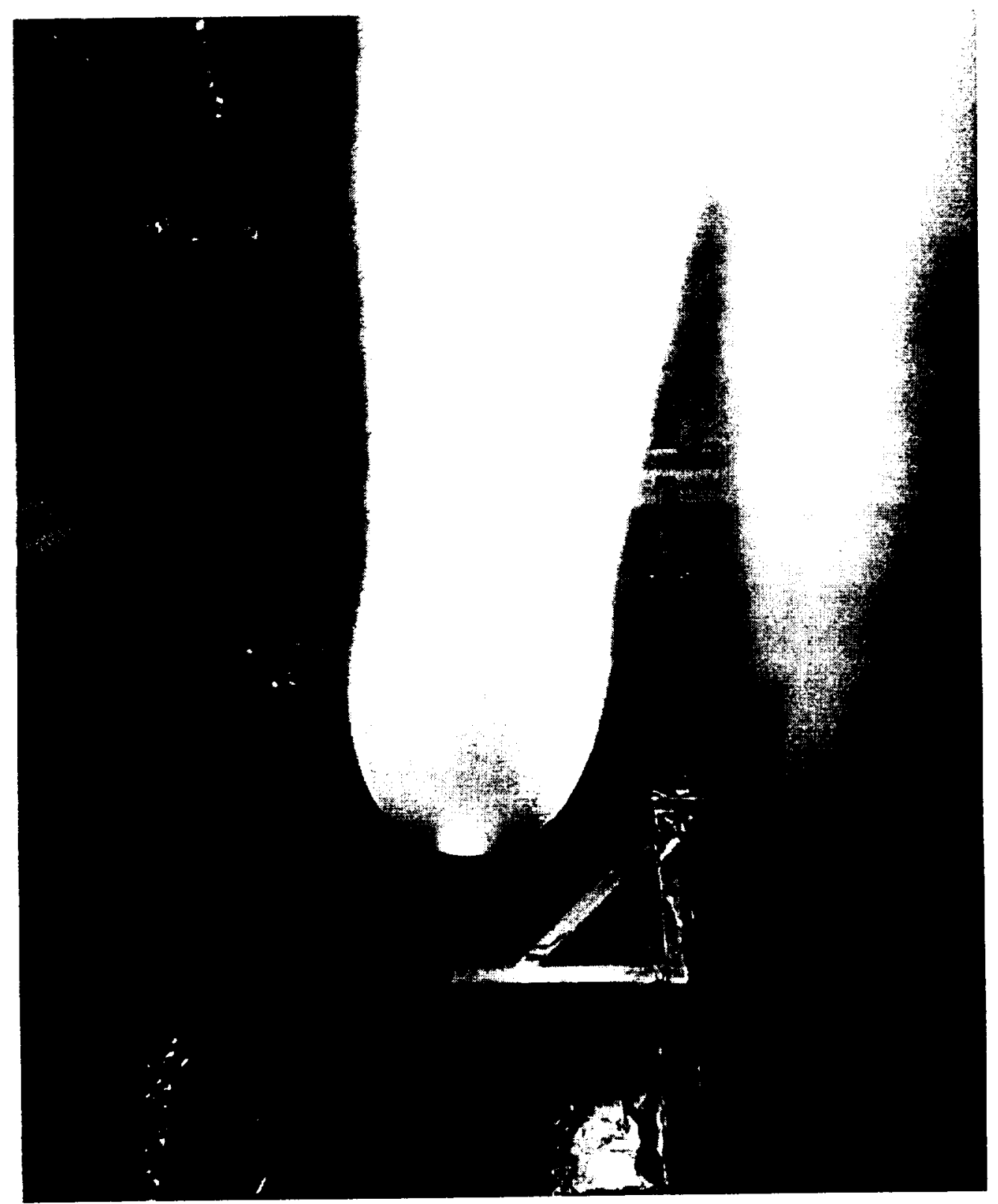




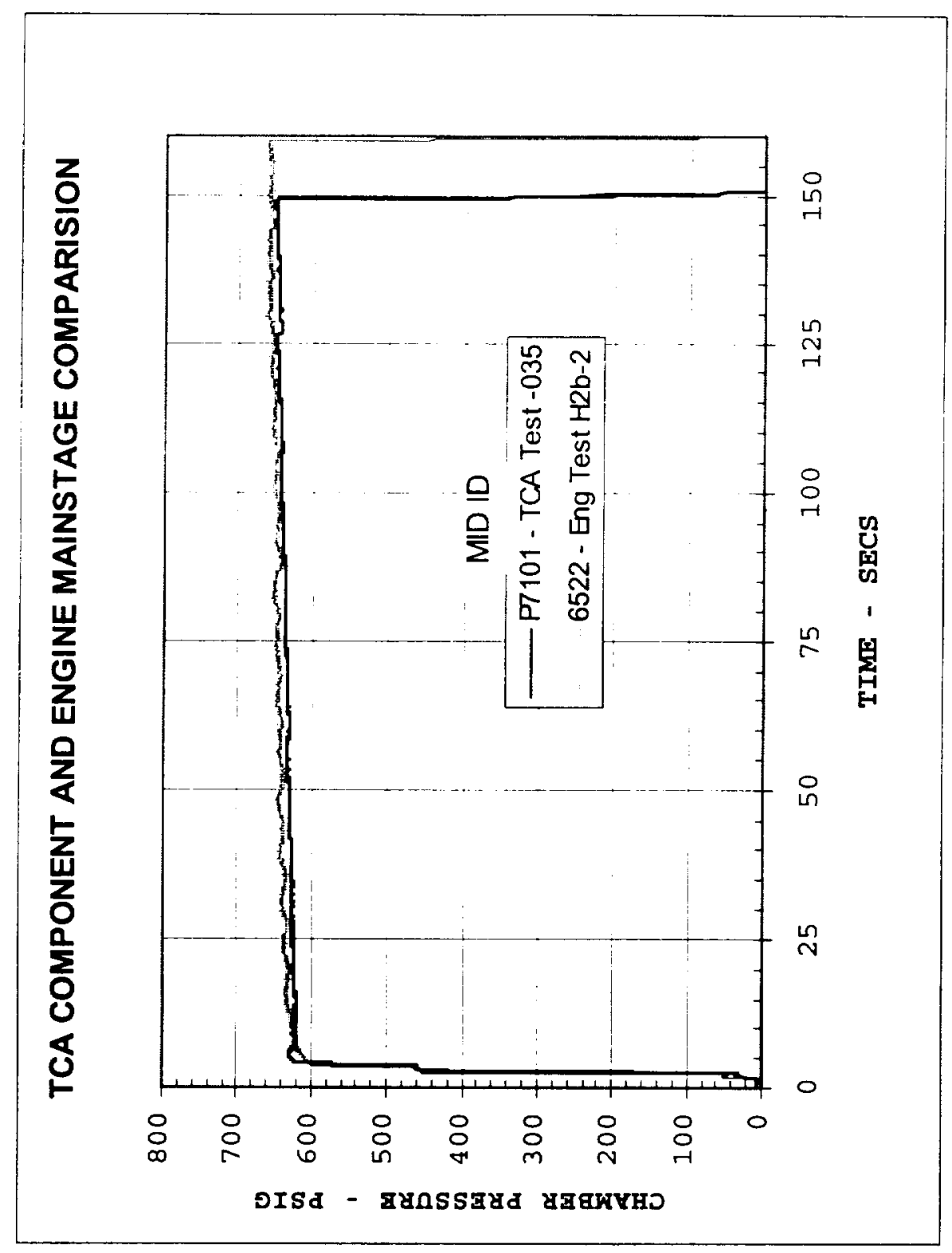


4545

math
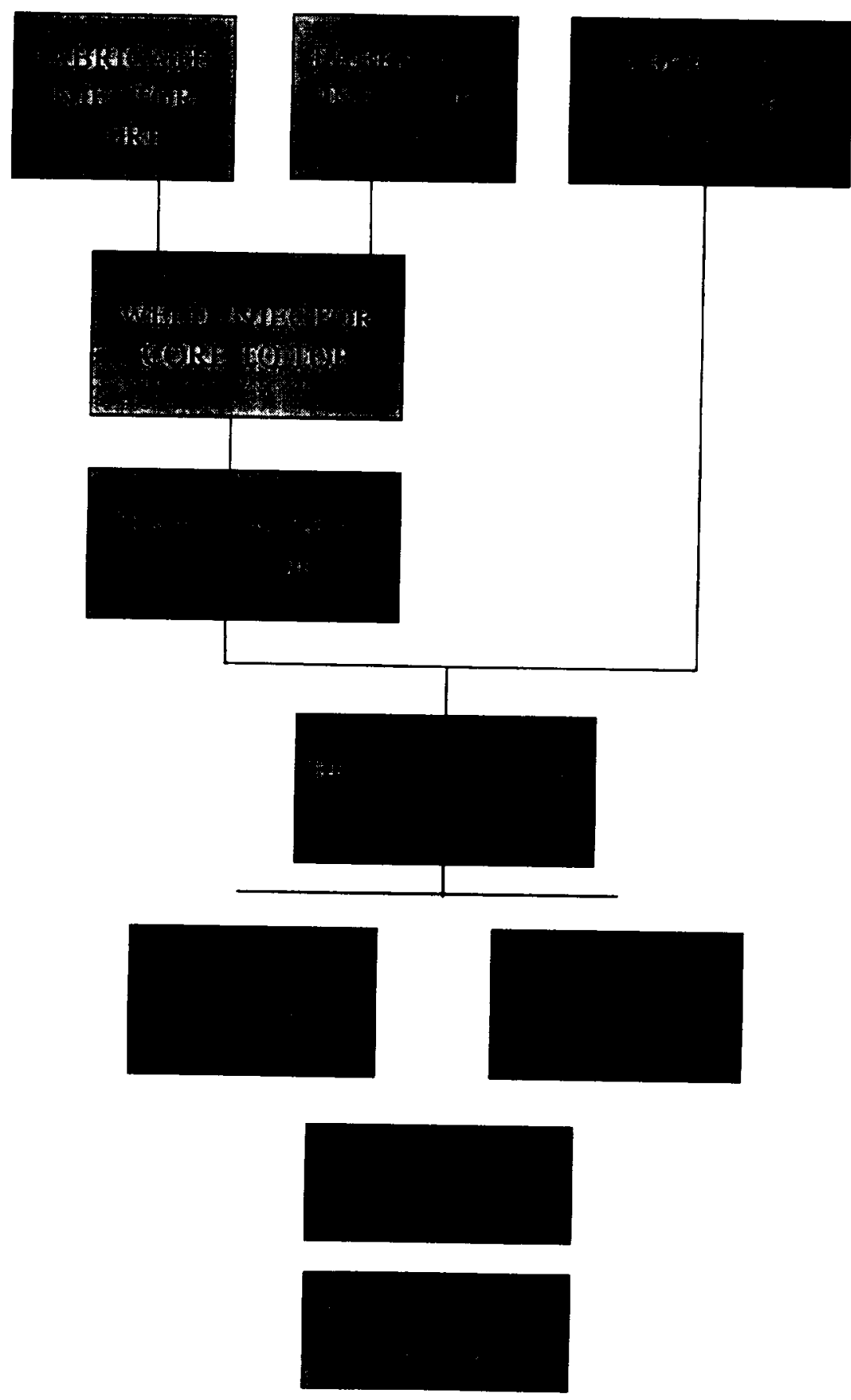